\title{
Uso de quercetina a longo prazo em ratos cirróticos ${ }^{1}$
}

\author{
Aline Miltersteiner ${ }^{2}$ \\ Diego Miltersteiner ${ }^{3}$ \\ Nelson Pereira Filho ${ }^{4}$ \\ Aline Rolim Frota ${ }^{5}$ \\ Pedro Bins Ely ${ }^{6}$ \\ Cláudio Galeano Zettler ${ }^{7}$ \\ Cláudio Augusto Marroni ${ }^{8}$ \\ Norma P. Marroni ${ }^{9}$
}

\begin{abstract}
Miltersteiner A, Miltersteiner D, Pereira Filho N, Frota AR, Ely PB, Zettler CG, Marroni CA, Marroni NP. Uso de quercetina a longo prazo em ratos cirróticos. Acta Cir Bras [serial online] 2003 MaioJun;18(3). Disponível em URL: http://www.scielo.br/acb.

RESUMO - Objetivo: Avaliar o uso a longo prazo do flavonóide quercetina em ratos cirróticos por ligadura de ducto biliar comum (LDB). Métodos: Foram utilizados 32 ratos machos Wistar, sendo submetidos à LDB ou simulação, e distribuídos em 4 grupos: 1) controle, 2) cirróticos, 3) cirróticos tratados com quercetina $50 \mathrm{mg} / \mathrm{kg}$, intraperitonealmente, desde o segundo dia após o procedimento cirúrgico; e 4) cirróticos tratados após o décimo quarto dia do procedimento cirúrgico. Analisouse a função hepática por meio de testes bioquímicos (BT e BD) e atividade enzimática (ALT, AST, FAe GGT). Na análise anatomopatológica, utilizou-se a coloração de Hematoxilina \& Eosina (H\&E) e de Picrosírius para fibrose. A análise estatística para avaliação de sobrevivência foi realizada pelo teste Kaplan-Meier. Resultados: Os resultados de sobrevivência dos oito animais de cada grupo foram: Grupo 1= 200 dias de sobrevivência; Grupo $2=46$ dias; Grupo $3=71$ dias; e o Grupo 4= 90 dias. Nos animais com ligadura de ducto biliar comum houve aumento das provas de função hepática e enzimáticas que se reduziu hipoteticamente com o tratamento com quercetina. Foram identificadas cirrose, congestão vascular porta e centrolobular na análise histopatológica por H\&E e Picrosírius. Conclusão: O uso da quercetina diminuiu de maneira significante as alterações bioquímicas provocadas pela cirrose, aumentando o tempo de sobrevivência dos animais com cirrose biliar secundária à LDB, como verificado pelo teste de análise de sobrevivência.
\end{abstract}

DESCRITORES - Cirrose hepática biliar. Quercetina. Ratos.

\section{Introdução}

Cirrose é uma doença crônica que acomete difusamente o fígado sem envolver necessariamente todos os lóbulos hepáticos, sendo histologicamente caracterizada por regeneração nodular do parênquima. Representa as conseqüências de uma resposta permanente de ferida-cicatrização à agressão hepática crônica, induzida por uma ampla gama de processos ${ }^{1,2}$. As conseqüências clínicas da cirrose variam desde a

1. Trabalho realizado no Laboratório de Fisiologia Digestiva da Universidade Federal do Rio Grande do Sul (UFRGS).

2. Mestranda pela Faculdade de Medicina da UFRGS, Professora do Curso de Fisioterapia da Universidade Luterana do Brasil (ULBRA).

3. Estagiário do $5^{\circ}$ ano do Curso de Medicina da ULBRA, campus Canoas, RS.

4. Estagiário do $6^{\circ}$ ano do Curso de Medicina da ULBRA.

5. Estagiária do $6^{\circ}$ ano da Fundação Faculdade Federal Ciências de Medicina de Porto Alegre (FFFCMPA).

6. Mestre pela UNIFESP - Escola Paulista de Medicina, Professor Adjunto do Curso de Medicina da ULBRA.

7. Doutor, Professor da Disciplina de Gastroenterologia e Patologia da FFFCMPA

8. Mestre e Professor da FFFCMPA.

9. Doutora, Professora e Coordenadora da Pesquisa do Curso de Fisioterapia da ULBRA e UFRGS. 
ausência de sintomas até a insuficiência hepática, e são determinadas tanto pela natureza quanto pela gravidade da hepatopatia subjacente, assim como pela magnitude da fibrose estabelecida ${ }^{3}$.

Diferentes estudos têm demonstrado a participação das espécies ativas de oxigênio na fisiopatologia da cirrose causada por estase biliar ${ }^{3,4}$. Além disso, é fato comprovado que há diminuição nas concentrações de glutationa e vitamina $\mathrm{E}$ - antioxidantes naturais do organismo - em pacientes com obstrução crônica de ducto biliar ${ }^{5}$. Vários antioxidantes e flavonóides têm sido referidos recentemente como eficazes para diminuir fibrose em modelos animais de cirrose biliar secundária à ligadura do ducto biliar, de cirrose por álcool ou por administração de tetracloreto de carbono $\left(\mathrm{CCl}_{4}\right)^{6}$. Os flavonóides são compostos que contêm grupos hidroxila fenólicos que lhes conferem uma ação antioxidante com potencial terapêutico ${ }^{7}$. Estudos in vitro têm mostrado que a quercetina e outros flavonóides inibem fortemente a produção de Óxido Nítrico e do Fator de Necrose Tumoral pelas células de Kupffer quando estimuladas pela injúria ${ }^{8}$. A quercetina combate com eficiência os ânions superóxido na isquemiareperfusão ${ }^{9}$. Os efeitos da quercetina e de outros flavonóides na doença hepática não estão bem elucidados.

Os flavonóides, por combaterem diretamente as espécies ativas de oxigênio ou aumentar a capacidade de reação hepática aos mesmos, poderiam contribuir para a redução do dano oxidativo hepático e da formação de fibrose causada pela obstrução biliar.

A quercetina é um destacado integrante do grupo de flavonóides e por sua ação antioxidante o seu desempenho terapêutico têm sido mencionado por vários autores no combate de estresse oxidativo ${ }^{9,10,11}$.

A administração de quercetina em ratos com obstrução do ducto biliar provoca melhora nos testes laboratoriais; porém, a real repercussão clínica deste tratamento ainda permanece sem completa elucidação.

O objetivo deste estudo foi avaliar o uso de quercetina a longo prazo em ratos cirróticos por ligadura de ducto biliar comum.

\section{Métodos}

Foram utilizados 32 ratos Wistar, machos, albinos, com média de peso de $280 \mathrm{~g}$ e com mais de 180 dias de vida. A cirrose biliar secundária foi provocada pela ligadura de ducto biliar comum (LDB) ${ }^{1,10}$ e o grupo controle foi submetido à simulação da obstrução do ducto biliar comum. Posteriormente foram divididos em 4 grupos: 1) Controle, 2) Cirróticos, 3) Ligados (LDB) com administração diária da quercetina a partir do segundo dia do procedimento cirúrgico, 4) Ligados (LDB) com administração diária da quercetina a partir do décimo quarto dia do procedimento cirúrgico. A dose utilizada da quercetina foi de $50 \mathrm{mg} / \mathrm{Kg}$ (Q50) do animal diluída em $0,7 \mathrm{~mL}$ de água destilada e a via de administração foi intraperitoneal (i.p.). A preparação da droga foi sempre feita na ausência de luz direta. Foram avaliados testes de função hepática tais como Aspartato aminotransferase (AST), Alanina aminotransferase (ALT), Gama glutamil transpeptidase (GGT), Fosfatase Alcalina e Bilirrubinas (direta e indireta).

A análise estatística da sobrevivência foi realizada pelo teste de Kaplan-Meier. O preparado histopatológico foi estudado a partir das colorações Hematoxilina e Eosina (H\&E) e Picrosírius. Todos estes procedimentos foram realizados no Laboratório de Fisiologia Digestiva do Instituto de Ciência Básica da Saúde da Universidade Federal do Rio Grande do Sul (UFRGS), Laboratório de Patologia da Faculdade Federal Ciências de Medicina de Porto Alegre (FFFCMPA) e Universidade Luterana do Brasil (ULBRA).

\section{Resultados}

Observou-se quanto à sobrevida dos animais ligados quando tratados com quercetina 14 dias após a ligadura (Grupo 1), 90 dias de sobrevivência, sendo significativa a diferença para $\mathrm{p}<0.05$ quando comparados com os cirróticos (Grupo 2) com sobrevida de 46 dias e com os animais ligados com uso da quercetina já às 48 horas após a ligadura (Grupo 3), com 71 dias de sobrevivência (Figuras 1 e 2). Os ratos do grupo 1 foram sacrificados com 200 dias.

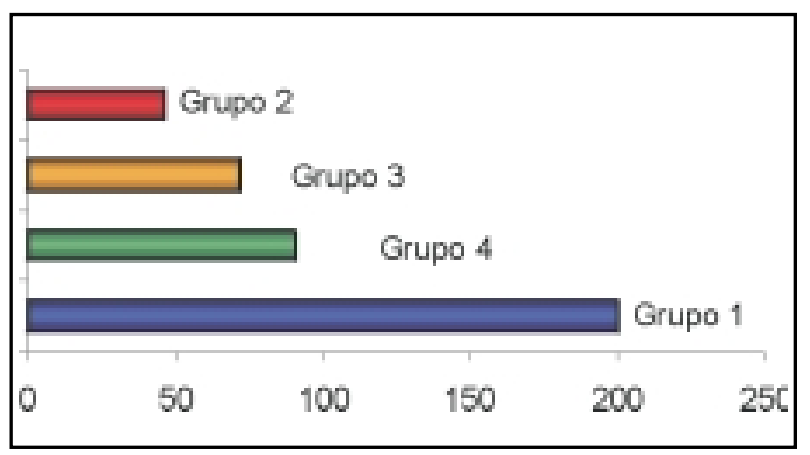

FIGURA 1 - Gráfico demonstrando que o tempo de sobrevivência nos respectivos grupos foi: $1=200$ dias; $2=46$ dias; $3=71$ dias; e $4=90$ dias. 


\section{Tempo de Sobrevivência}

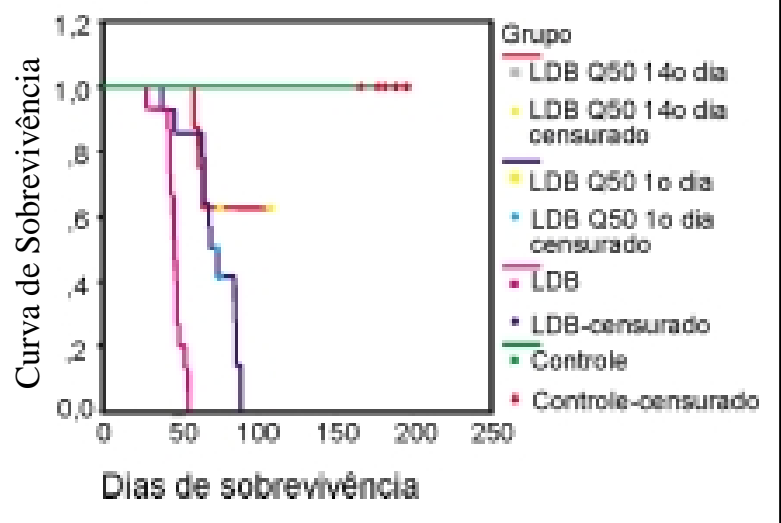

FIGURA 2 - Gráfico demonstrando a curva de sobrevivência, Teste Kaplan- Meier.

Houve uma diferença significante $(\mathrm{p}<0.05)$ nos níveis de Fosfatase Alcalina (Figura 3) e Gama Glutamil Transpeptidase (Figura 4) dos animais tratados com quercetina em comparação com os cirróticos (285 U/L).

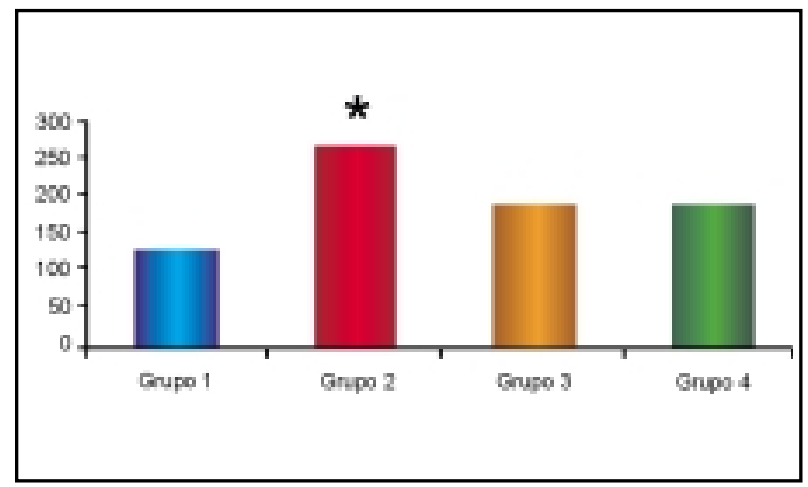

FIGURA 3 - Gráfico informando a medida da Fosfatase Alcalina $(\mathrm{FA}-\mathrm{U} / \mathrm{L}),(*=\mathrm{p}<0.05)$.

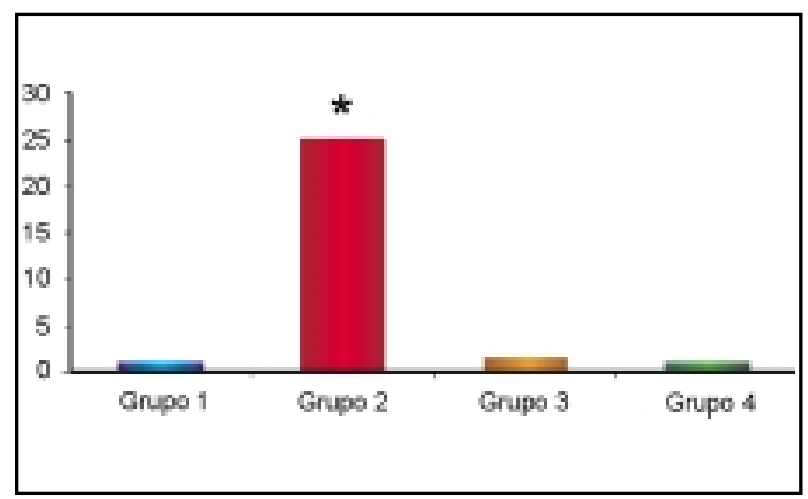

FIGURA 4 - Gráfico apresentando os valores da Glutamil Transpeptidase (GGT - U/L).

Gama$(*=\mathrm{p}<0.05)$.
Os níveis de Bilirrubina total e direta nos animais cirróticos apresentaram-se significantemente aumentados quando comparados com os demais grupos ( $\mathrm{p}<$ 0.05) (Figura 5). O mesmo ocorrendo com AST (Figura 6) e ALT (Figura 7) quando se comparam cirróticos e cirróticos com uso de quercetina.

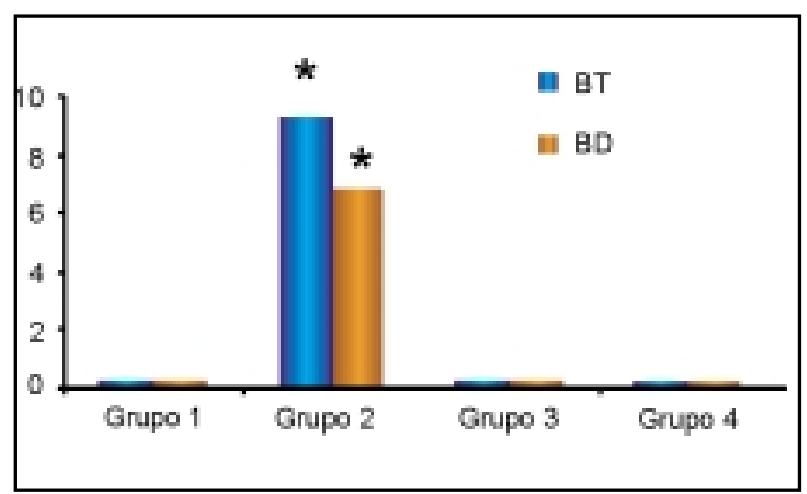

FIGURA 5 - Gráfico informando os valores da Bilirrubina total e bilirrubina direta $(\mathrm{mg} / \mathrm{dL}),(*=\mathrm{p}<0.05)$.

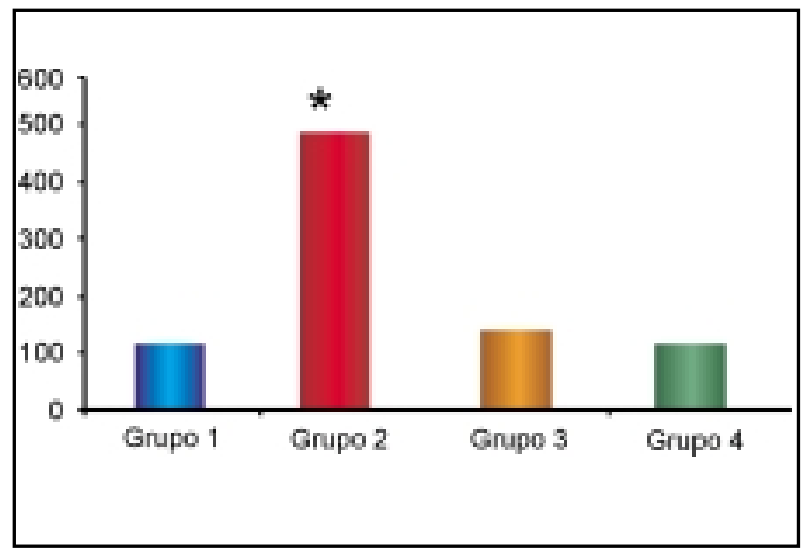

FIGURA 6 - Gráfico demonstrando os valores da Aspartato aminotransferase $(\mathrm{U} / \mathrm{L}),(*=\mathrm{p}<0.05)$.

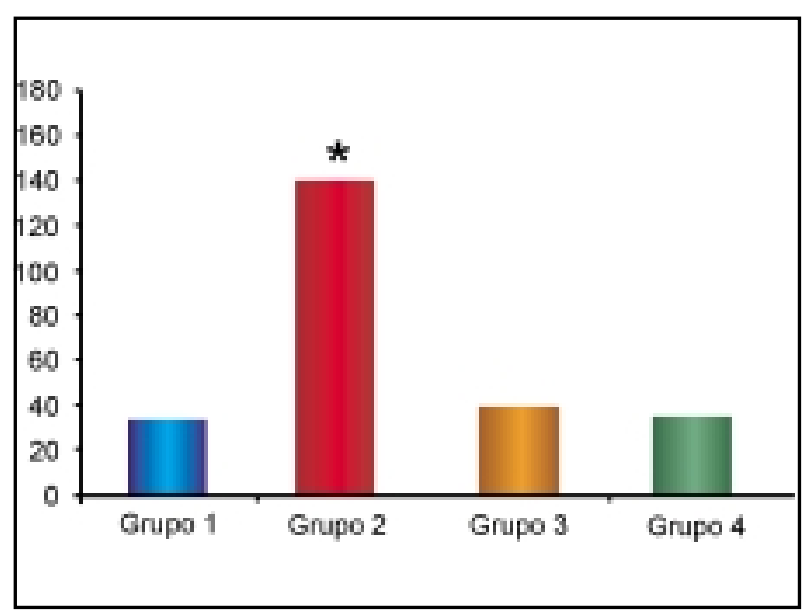

FIGURA 7 - Gráfico informando os valores da Alanina Aminotransferase (U/L). $(*=p<0.05)$. 
No estudo histológico descritivo comparativo entre os quatro grupos, avaliados os parâmetros em cruzes (Tabela 1), foram observados por meio da técnica de Picrosírius e H\&E: intensa fibrose periporta e porta (Figura 9), cirrose, intensa hiperplasia de ducto e congestão vascular porta e centrolobular, no grupo 2; moderada fibrose periporta (Figura 10), hiperplasia de ducto, moderada congestão vascular porta e centrolobular, moderado infiltrado inflamatório porta e lobular no grupo 3; e leve fibrose periporta sem fibrose porta, moderada congestão vascular porta, moderado infiltrado porta no grupo 4 (Figura 11). No grupo 1, não foram encontradas alterações como fibrose e congestão, pois os animais faziam parte do grupo controle (Figura 8).

TABELA 1 - Resultados da análise anatomopatológica dos quatro grupos.

\begin{tabular}{c|c|c|c|c|c|c}
\hline Grupos & Cirrose & $\begin{array}{c}\text { Fibrose } \\
\text { periporta }\end{array}$ & $\begin{array}{c}\text { Fibrose } \\
\text { porta }\end{array}$ & $\begin{array}{c}\text { Hiperplasia } \\
\text { ductal }\end{array}$ & $\begin{array}{c}\text { Congestão } \\
\text { vascular } \\
\text { centrolobular }\end{array}$ & $\begin{array}{c}\text { Congestão } \\
\text { vascular } \\
\text { porta }\end{array}$ \\
\hline $1(\mathrm{SO})$ & Não & - & - & - & - & - \\
\hline $2(\mathrm{LDB})$ & Sim & $* * * / 4$ & $* * * * / 4$ & $* * * * / 4$ & $* * * / 4$ & $* * * / 4$ \\
\hline $3(48 \mathrm{~h})$ & Não & $* * / 4$ & - & $* * / 4$ & $* * / 4$ & $* * / 4$ \\
\hline $4\left(14^{\circ}\right.$ dia $)$ & Não & $* / 4$ & - & - & - & $* * / 4$ \\
\hline
\end{tabular}

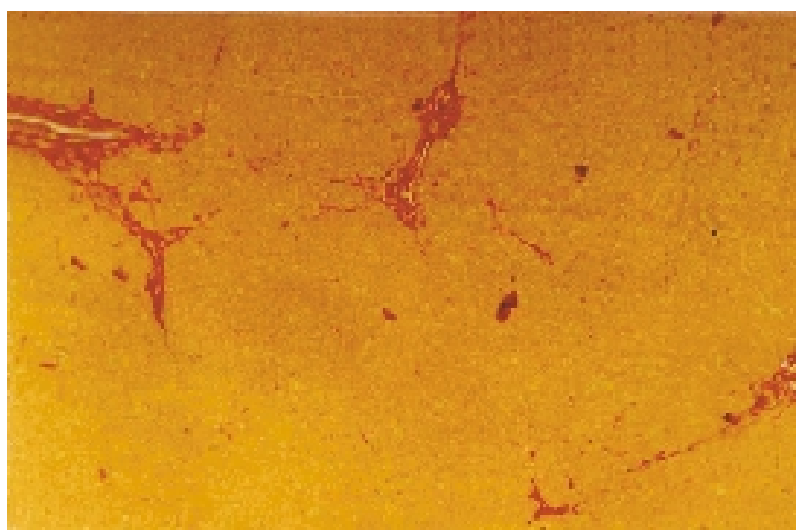

FIGURA 8 - Fotografia apresentando o preparado histológico do grupo 1 (controle) com coloração Picrosírius, 100x.

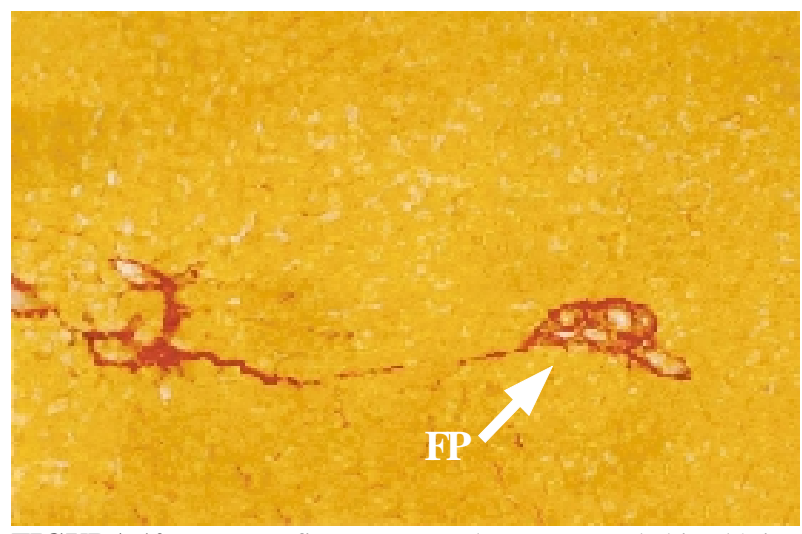

FIGURA 10 - Fotografia apresentando o preparado histológico do grupo 3 (ligados - LDB tratados com quercetina 48h) com coloração Picrosírius, 200x. ( $\mathrm{FP}=$ fibrose periporta).

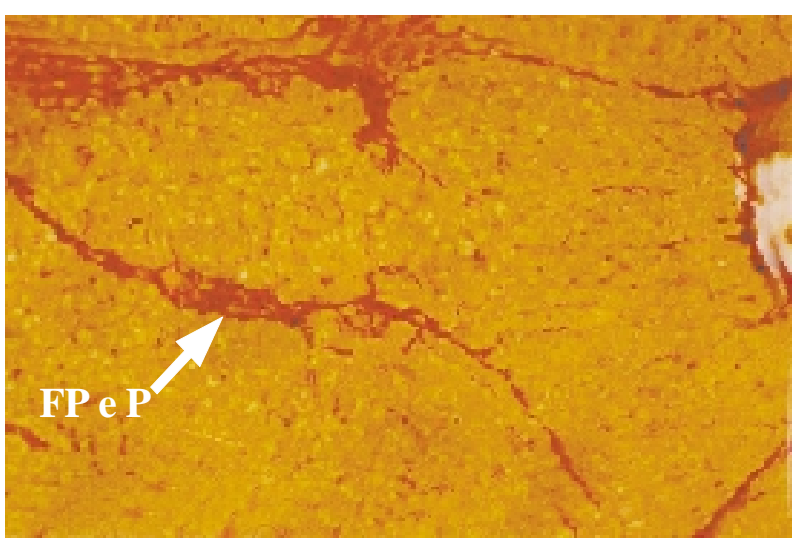

FIGURA 9 - Fotografia apresentando o preparado histológico do grupo 2 (cirróticos), com coloração Picrosírius, 100x. (FP= fibrose periporta e $\mathrm{P}=$ porta).

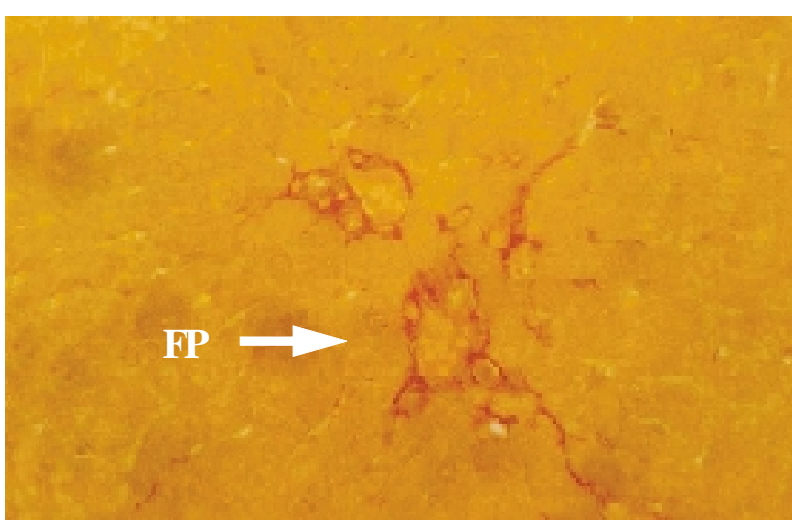

FIGURA 11 - Fotografia apresentando o preparado histológico do grupo 4 (LDB - ligados tratados . com quercetina 14 dias) com coloração Picrosírius, 100x. ( $\mathrm{FP}=$ fibrose periporta). 


\section{Discussão}

Estudos prévios têm demonstrado que no modelo equivalente de cirrose biliar secundária à ligadura do ducto biliar comum se estabelecem as características próprias da doença em torno de vinte e oito dias ${ }^{12,13}$. Neste período, encontram-se alterações provenientes da reação inflamatória causada pelo refluxo biliar, desorganização da arquitetura natural do parênquima com áreas inflamatórias presentes e, outras já com fibrose e deposição colágena, que são características que determinam a cirrose hepática. PERES e colaboradores (2000), demonstraram que a cirrose biliar secundária está associada com o aumento de espécies ativas de oxigênio, avaliados pela formação de malonadealdeído e produção da enzima glutationa hepática ${ }^{14}$.

Os flavonóides e outros compostos fenólicos naturais se encontram nos vegetais, no chá, nos vinhos tintos, formando parte da dieta alimentar, sendo a mais importante a quercetina.

O efeito farmacológico dos flavonóides se deve à sua ação na inibição de certas enzimas e sua capacidade antioxidante.

Os flavonóides são potentes depuradores de espécies ativas de oxigênio e queladores de metais. A quercetina depura ânions superóxidos e radicais hidroxilas. Os efeitos dos flavonóides quercetina e rutina em ratos com cirrose biliar secundária avaliados por Peres e colaboradores, mostrou uma diminuição significante de fibrose e na concentração hepática de colágeno, fatos evidenciados nesse estudo por meio da avaliação de fibrose por Picrosírius.

O tratamento com flavonóide quercetina, por sua ação de combate ao estresse oxidativo causado pela inflamação, determinou aumento no tempo de sobrevivência nos animais cirróticos. Como já descrito anteriormente, foram realizados dois esquemas de tratamento. O primeiro consistia em iniciar o tratamento dos animais quarenta e oito horas após o procedimento cirúrgico e o segundo consistia em tratar esses animais somente a partir do décimo quarto dia após o procedimento de ligadura do ducto biliar. A dose empregada nesse trabalho foi eficaz em outros trabalhos publicados, quando se verificou que não havia mutagenicidade ou citotoxicidade nas doses utilizadas. Através de teste de micronúcleo e ensaio cometa.

A quercetina exerce seu efeito antioxidante se administrado a partir do décimo quarto dia de tratamento. Sabe-se que por volta do décimo quarto dia após o procedimento cirúrgico já encontram-se sinais típicos de inflamação no parênquima hepático, bem como o início da desorganização da arquitetura hepática.
Sugere-se que tenha impedido a lesão causada pelas espécies reativas de oxigênio por ação antioxidante.

O uso da quercetina logo após o procedimento cirúrgico não foi eficaz a julgar pela sobrevivência dos animais, possivelmente porque o fígado não estava tão lesado e os antioxidantes endógenos combateriam as espécies ativas de oxigênio aí formadas, fato já observado por nosso grupo e por PERES e colaboradores (2000) quanto ao uso de rutina e quercetina em animais normais.

O papel protetor da quercetina nesse modelo experimental foi observado nas análises bioquímica e enzimáticas e na diminuição da fibrose pelo estudo histológico por Picrosírius, a partir da análise dos fígados dos animais sobreviventes. A partir dos dados obtidos, o uso crônico e continuado de quercetina na dose utilizada nesse estudo, não apresentou toxicidade ao longo do tempo de administração levando aos animais submetidos à ligadura (LDB), a uma maior sobrevida do que os não tratados.

$\mathrm{O}$ tratamento com quercetina a partir de quarenta e oito horas do procedimento cirúrgico, inicia em um momento no qual o fígado encontra-se com muito pouco processo inflamatório presente. Neste momento, as reservas antioxidantes estão ao nível máximo, necessitando de menos auxílio no controle das reações oxidativas. Sugere-se que haja desenvolvimento de tolerância e que o organismo desenvolva meios de eliminação como já foi observado por nosso grupo e por PERES e cols. (2000), a ação do flavonóide não é observada em animais normais. Então, a administração da quercetina a partir desse momento não apresenta valor benéfico preponderante sendo o organismo capaz de combater a oxidação presente. A ação da quercetina após instalada a cirrose biliar secundária, a saber pela resposta às provas de função hepática e ao estudo histológico realizado, mostrou um poder antioxidante protetor dos flavonóides sobre o parênquima hepático ${ }^{15}$.

Os dados obtidos demonstraram que o uso crônico e continuado da quercetina não apresentou toxicidade ao longo do tempo estudado e os animais tratados (após 14 dias) com a droga apresentaram um maior tempo de sobrevivência do que os não tratados.

\section{Conclusões}

A quercetina aumentou o tempo de sobrevivência dos animais com cirrose biliar secundária à ligadura de ducto biliar, como verificado pelo teste de análise de sobrevivência (Teste de Kaplan-Meier).

O uso do flavonóide quercetina na dose de $50 \mathrm{mg} /$ $\mathrm{Kg}$ intraperitoneal diminuiu significantemente as alterações bioquímicas e enzimáticas provocadas pela cirrose. 
O esquema terapêutico com tratamento a partir do décimo quarto dia após o procedimento cirúrgico mostrou ser mais eficaz, considerando-se a sobrevivência dos animais, do que logo após (48 horas) a indução de cirrose por ligadura de ducto biliar.

\section{Referências}

1. Hunt DR. The identification of risk factors and their application to the management of obstructive jaundice. Aust N J Surg 1980; 50: 476-80.

2. Sokol RJ. Lipid peroxidation in cholestasis. In: Paumgartner G, Stiehl A, Gerok W, editor. Pediatric Colestasis. Dordrecht: Kluwer; 1992. p 75-80.

3. Tasi LY, Lee KT, Tai SM, Lee SC, Yu SH. Change of lipid level in blood and liver tissue of patients with obstructive jaundice. Clin Chim Acta 1993; 215: 41-50.

4. Forestier M, Solioz M, Isbeki F, Talos F, Reichen J, Khrahenbuh S. Hepatic mitochondrial proliferation in rats with secondary billiary cirrhosis: time courses and mechanisms. Hepatology 1997; 26: 386-91.

5. Singh S, Shackleton G, Ah Sing E, Chakraborty J, Bailey ME. Antioxidant defenses in the duct-ligated rat. Gastroenterology 1992; 103: 1625-9.

6. Muriel P. Suárez OR, González PM, Zúñiga L. Protective effect of S-adenosylmethionine on liver damage induced by billiary obstruction in rats: a histological, ultrastructural and biochemical study. J Hepatol 1994; 21: 95-102.

7. Jang M, Cai L, Udeani GO, Slwoing KV, Thomas CF, Beecher DM. The red wine phenolics trans-resveratrol and quercetin block human platelet aggregation in eicosanoid synthesis: implication for protection against coronary heart disease. Clin Chim Acta 1995: 235: 207-19.

8. Kawada N, Seki S, Inoue M, Kuroki T. Effect of antioxidants, resveratrol, quercetin, and $\mathrm{N}$-acetylcysteine, on the functions of cultured rat hepatic stellate cells and Kupfer cells. Hepatology 1998: 27: 1265-74.

9. Huk I, Brovkovich V, Nanobash V, Weigel G, Neumayer C, Partyka L, et al. Bioflavonoid quercetin scavenge superoxide and increase nitric oxide concentration in ischaemiareperfusion injury: an experimental study. Br J Surg 1998; 85:1080-5.

10. Peres W, Tuñón MJ, Collado PS, Herrmann S, Marroni N Gallego JG. The flavonoid quercetin ameliorates liver damage in rats with biliary obstruction. J Hepatol 2000; 33: 742-50.

11. Jonavic SV, Steenken S, Simic MG, Hara Y. Antioxidant proprierties of flavonoids: reduction potentials and electron transfer reactions of flavonoid radicals. In: Rice Evans C, Packer L. Flavonoids in health and disease. New York: Marcel Deker; 1998. p 137-61.

12. Kountouras J, Billing BH, Scheuer PJ. Prolonged bile duct obstruction: a new experimental model for cirrhosis in the rat. Br J Exp Pathol 1984; 65:305-11.

13. Lee SS, Girod C, Braillon A, Hadengue A, Lebrec D. Hemodinamic characterization of chronic bile duct-ligated rats: effect of pentobarbital sodium: hemodinamics in bile ductligated Rats 1986; G177-179.

14. Tuñon MJ, Peres W, Collado PS, Mattos S, Marroni N, Gonzáles-Gallego J. Antioxidant effects to the flavonoid Quercitin in billiary obstructed rats. Department of physiology, University of León, 2071 León, Spain 267-73.

Miltersteiner A, Miltersteiner D, Pereira Filho N, Frota AR, Ely PB, Zettler CG, Marroni CA, Marroni NP. The long term use of quercetin in cirrhotic rats. Acta Cir Bras [serial online] 2003 MayJun;18(3). Available from URL: http://www.scielo.br/acb.

ABSTRACT - Purpose: The long term use of quercetin flavonoid was evaluated in cirrhotic rats by common biliary duct bondage (LDB). Methods: 32 male Wistar rats were submitted to LDB or simulation, and distributed in 4 groups: 1) control, 2) cirrhotic, 3) cirrhotic treated with quercetin the second day after the surgical procedure; and 4) cirrhotic treated with quercetin after the fourteenth day of the surgical procedure. The hepatic function was analyzed through biochemical tests (TB and DB) and enzymatic activity (ALT, AST, AP and GGT). In the anatomopatological analysis, Hematoxilin \& Eosin (H\&E) coloration, and Picrosirius (for fibrosis) were used.The statistical analysis for survival evaluation was accomplished by the Kaplan-Meier test. Results: The results of survival of the eight animals of each group were: Group $1=200$ days of survival; Group $2=46$ days; Group $3=71$ days; and the Group $4=90$ days. In the animals with bondage of common biliary duct, there was an increase of the hepatic and anzymatic function tests, which was reduced with the treatment with quercetin. Cirrhosis, portal and centrolobular vascular congestion, were identified in the histopatological analysis with H\&E and Picrosirius. Conclusion: The use of quercetin decreased significantly the biochemical alterations caused by cirrhosis, increasing the time of survival of the animals with secondary biliary cirrhosis due to LDB.

KEY WORDS - Secondary biliary cirrhosis. Quercetin. Rats.

Conflito de interesse: nenhum

Correspondência: Fonte de financiamento: FAPERGS e ULBRA

Aline da Rosa Miltersteiner

Rua 24 de agosto, 834

93280-000 Esteio - RS

Tel: (51)9118-8481 - alinemilt@terra.com.br

Data do recebimento: 20/12/2002

Data da revisão: 05/01/2003

Data da aprovação: 10/02/2003 